\title{
Augmented Reality in Context of Industry 4.0
}

\author{
Kristýna Havlíková \\ Západočeská univerzita v Plzni, Fakulta strojní, Katedra průmyslového inženýrství a \\ managementu \\ Univerzitní 2732/8, 30614 Plzeň, Česká republika \\ khavliko@kpv.zcu.cz
}

\begin{abstract}
Annotation: Augmented Reality systems represent technological solutions allowing integration of virtual and real worlds. As the importance of information in technology rises, AR has become a great contribution to many applications. Already since the origins of AR, industry has always belonged among the key application areas. The recent advances in both wearable and portable devices supporting AR significantly increase the applicability of AR. In connection with the new challenges arising with the development of Industry 4.0, AR systems present a great tool to productivity improvement and user experience enhancement. This is a reason, why Industrial augmented reality is considered to be one of the key parts of Industry 4.0 concepts. The principal aim of this study is to describe AR technology with emphasis put on manufacturing industry and its role in Industry 4.0 initiatives.
\end{abstract}

\section{Introduction}

The fourth industrial revolution creates new challenges for industries and manufacturing companies to improve and change their business. The products must be more personalized, the processes more flexible, faster and at lower costs. In order to meet these expectations, the companies invest in new emerging technologies that help to increase the flexibility of the manufacturing processes and support the decision-making procedures. One of the essential technologies supporting the challenges of the quickly developing Industry 4.0 is AR. In manufacturing application AR is discussed as a potentially powerful tool in order to improve productivity, process efficiency and flexibility. On the other hand, AR is still not widely spread in manufacturing and offers great potential for use and improvement.

\section{Augmented Reality}

The rapid growth of the computing power, increasing storage possibilities and still lower mobile device costs are opening new opportunities for usage of AR. One of the fields that has been exploiting the expanding functions offered by the mobile devices is AR which can be defined as a branch of computer research that focuses on the possibilities of combining the real world with data generated by computer. The mobile phones, smartphones, PDAs and others are cheap and light hardware platforms with a simple and well-known user 
interface which are nowadays widespread. Moreover, practically all of them are equipped with camera and display with high resolution which allows the user the see-through way of interaction, which makes them an interesting alternative to classic hardware solutions.

\subsection{Definition of Augmented Reality}

Although the core technology described in this study is $A R$, it is also appropriate to determine the difference between $A R, V R$ and MR. Whereas $A R$ is a technology which enables the access to digital information and overlays that information with the physical world, VR allows users to take part in a simulated reality experience. MR (Mixed Reality) compared to AR offers the user the interaction with digital objects placed in the real surroundings. The above-mentioned terms were set into context by Paul Milgram, who defined the Reality-Virtuality Continuum as shown in Figure 1 [1]. In Milgram's definition of $A R$, the whole area of real-to-virtual environment is described. Milgram introduces 4 main sections:[1]

- Real environment

- Augmented Reality

- Augmented Virtuality

- $\quad$ Virtual Environment (VR)

Augmented Virtuality was here defined as part of mixed reality continuum, in which the real objects are added to virtual ones. As well as VR these both work in the virtual environment compared to AR which is based on the real environment. [1]

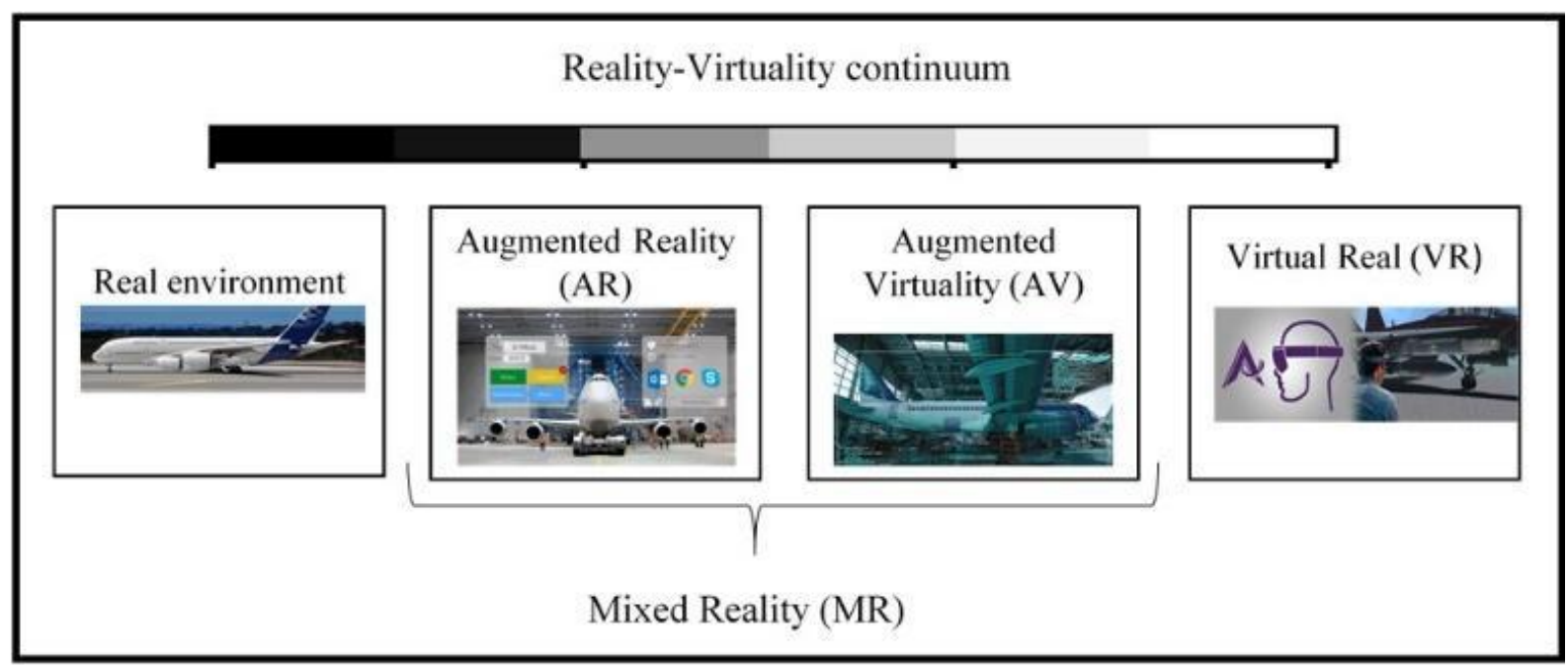

Figure 1 - Reality-Virtuality continuum

Although AR has been a popular and quickly developing concept mainly in the last years, its origins are dated back to the 1960s. Authors assign the first 
reference to a Harvard Professor Sutherland who invented the first AR prototype device in 1968. It was the first Head Mounted Display (HMD), which was worn on head and had inbuilt a display optic. This optic enabled the user the immersion into a visually simulated 3D surroundings. [2]

However, this innovation stayed unexplored for many years after its first appearance. It was not until 1990s when the popularity of AR began to rise when scientists Tom Caudell and David Mizell developed first AR system by using an HMD. The main goal of this experimental AR system was to simplify the manufacturing process in aviation. [2]

In the upcoming years, many researchers were developing prototypes to simulate various industrial applications of AR.

AR technology was expanding and so was the interest in it not only of the scholars and scientists but also the companies in many areas of application, such as Military, Medicine, Aviation, Engineering or Manufacturing.

The rapid growth of the computing power, increasing storage possibilities and still lower mobile device costs have been opening more and more new opportunities for AR technology usage. Significant hardware progress as well as development of software like AR Toolkit considerably conduced to the progress of AR systems. [3]

Mobile devices and smartphones have become a necessity and fundamental component of modern consumption and life. As the technology improved, its application by companies started to be more common. Some examples of practical usage of AR can be mentioned, such as Volkswagen's app MARTA specialized in car manuals, instructions for mechanics but also in cosmetic purposes of car design. Another well-known practical application was Google Glass, revealed by Google in 2014. Although the success of Google Glass did not live up to initial expectations it was a very important step in $A R$ development.

Much more successful application of wearable AR system were HoloLens introduced by Microsoft in 2016. Tests showed that confirmed that this technology contributes to error decrease alongside the boosting of productivity and efficiency. [3]

According to the recent development suggestions, future with importance of augmented reality should be increasing significantly. It is expected that the customers in general will be working with a reality enriched with virtual content. AR is therefore a very promising field which is constantly growing and has high impact on a lot of fields of usage.

There is a vast array of definitions of $A R$ and authors differentiate in defining AR. In general AR can be defined as a technology which is based on real-time data visualisation.

Rauschnabel [5] defines AR as an innovative media format that integrates virtual information into a user's perception of the real-world. Milgram and 
Kishinott [2] defined AR in short to be a way in which the real-world is augmented with virtual objects.

Craig [6] specified AR as "medium in which digital information is overlaid in the physical world that is in both spatial and temporal registration with the physical world and that is interactive in time to create the visual alignment of virtual content with real- world contexts".

Azuma et al. [7] describe Augmented Reality as a system that supplements the real world with virtual (computer-generated) objects that appear to coexist in the same space as the real world. These systems combine virtual and real objects in a real environment, also they are running interactively and in real time and align real objects and virtual ones geometrically in the real world.

The definitions are therefore similar to the definition of Virtual Reality (VR). The main difference is the fact that whereas in VR the user is usually completely separated from the reality by using of special goggles and moves constantly in a completely virtual world, the user in AR is never disconnected from reality.

AR applications typically combine a real-world image with graphics and text, updating in real time.

Azuma points out that the use of AR does not have to be eliminated only to sight, AR can apply to other senses including hearing, touch and smell. Azuma also discusses a subset of AR in so called mediated or diminished reality. This subset represents the alternative option explaining that the core of $A R$ is not always based on adding or placing a virtual object over a realworld scene. On contrary, the AR application sometimes requires the removal of an existing object in the real-world scene in order to be replaced. [7]

\subsection{Supportive technologies}

AR application requires the usage of relatively complex and advanced technologies which have been a significant obstacle to more advanced application of AR. With the rapid evolution of these technologies, AR is becoming more accessible and affordable. In the following section the key information regarding the supportive technology with focus on displaying and tracking is summarized.

\subsubsection{Displays}

There are several main categories which can be used to view the merged real and virtual environments: [4]

- Head-mounted Displays

- Handheld Displays

- Spatial Displays

HMD are mounted on the head of the user. HMD therefore enable the aerial view of real and virtual environment. These displays can work in two different 
ways, optical see-through (OST) and video see thorough displays (VST) as shown in Figure 2 [8].

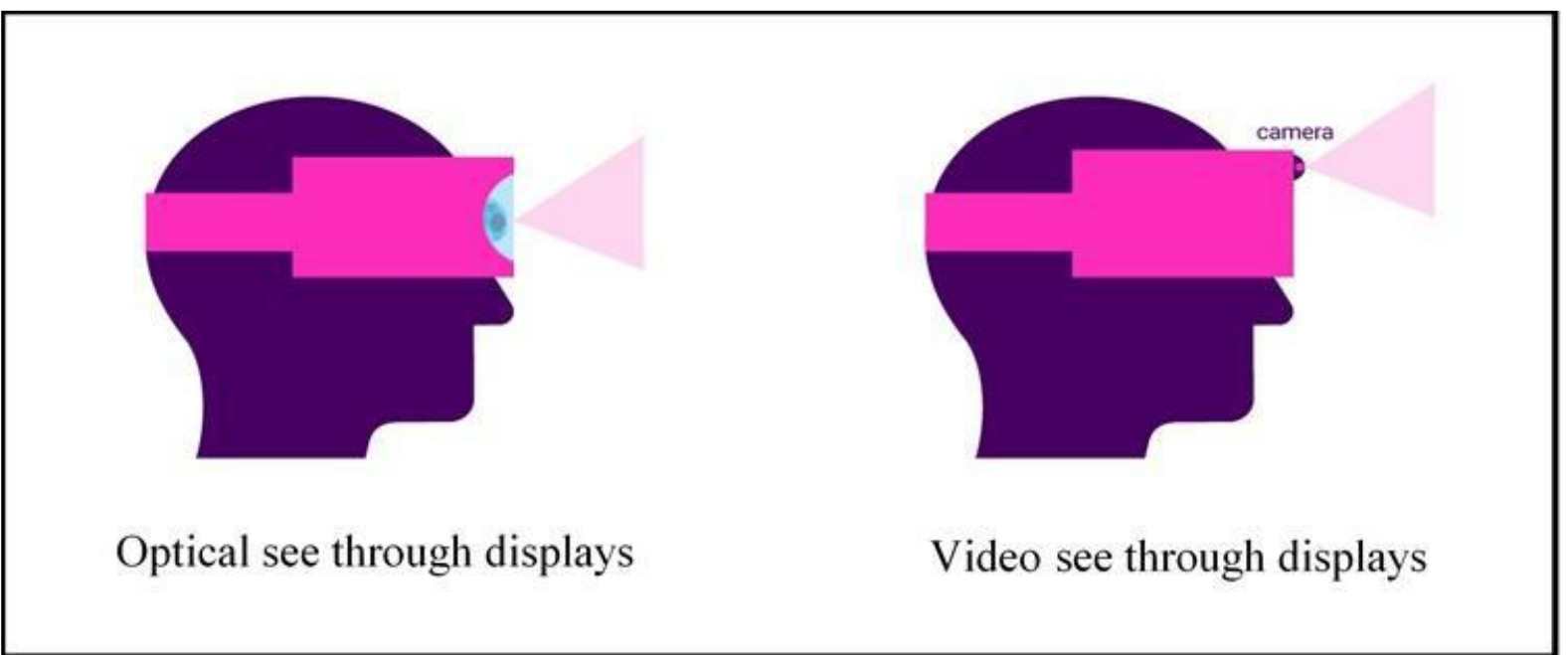

Figure 2 - Optical see through display, Video see through display

VST are equipped with 2 cameras which capture real surroundings and transfer these surroundings in real-time in to the graphics processors. The audio-visual is processed and projected on the screen. Advantages and disadvantages of VST can be described. The user can for instance control the light intensity or contrast of the real-surroundings and virtual elements. To the main disadvantages of VST belong narrow field of vision caused by the positioning of the camera, eye-offset and low resolution.[8]

OST on contrary uses optical elements which are partially reflective and partially transmissive. Due to the mirrors which transmit light it is possible to see the real-world environment. At the same time, the computer created content is projected on the display which is positioned sideways or in front of the mirror. [8]

The advantages of OST are for example better natural resolution or their ability to work without access to power. On the other hand, OST cannot control contrast or brightness.

HHDs are systems held by user's hand, typically tablets or smartphones. HHDs use VST technology. The principal benefit of HHD is its portability. Also, due to the fast evolution of smartphones all over the world the accessibility of the technology is quickly rising. The vast majority of these devices are equipped with cameras and Global Position Systems (GPS) being therefore an excellent platform for AR application.

The disadvantages of HHDs are for example high power consumption and relatively small display.

Spatial displays are not connected with the user's body compared to HMD and HHD. The technologies used in spatial displaying to display information are projectors, VST, OST. 
Among the most general problematic areas of use concerning the optimal characteristics of the displays belong insufficient resolution, brightness, contrast and limited field of view.

Regarding the practical use of these AR displays the weight, size, costs and power consumption are the main concerns.

\subsubsection{Tracking}

The key goal of the AR registration is the correct tracking of viewing orientation of the user. To make the system of augmented reality work correctly, it is necessary to determine the relative position and orientation of users who move in it. Some technologies allow multiple users to be tracked, however, this functionality is not always easy to achieve.

The visual tracking usually needs to modify the environment by placing the markers. A marker is a physical object placed in the scene which is picked up by a sensor and used for quick detection and registration. Markers are often symbols or pictures. [10]

Another important factor is positioning. It is necessary to decide whether it works only in a limited, pre-prepared one space (for example in a closed room) or if it is possible to determine the position even in an unbounded space, e.g. outside the building.

\subsubsection{Active technologies}

Active technology is characterized by the use of transmitters that are located in known positions in a real environment. A receiver is used to determine the position, which measures the distance relative to several other transmitters and by triangulation determines the position. To determine the orientation more receivers are needed in a constant relative position. The signal can be radio waves, light or ultrasound. The distance can be determined, for example, based on the flight time of the signal or its strength.

According to Yokokohji [11] the well-prepared indoor environment can support a very good registration. The advantage of this method is accuracy and reliability. The disadvantage is that the system works only to a limited extent and a pre-prepared space, which must be provided with a large number of systematically deployed transmitters. Another disadvantage of active transmitters is that they require for their operation constant supply of energy. [12]

Also, advantages of hybrid-tracking are often used. An example of such hybrid tracking can be Spatial Mapping.

Spatial mapping describes the process of an AR device literally mapping the space. This is done through computational geometry and computer-aided engineering that create a mesh that lays over the environment. All devices generate this mesh, which looks like a series of triangles placed together like a fishing net. Spatial mapping makes it possible to place objects on real 
surfaces. This helps anchor objects in the user's world and takes advantage of real-world depth cues. [13]

When combining e.g. magnetic and video sensors the individual weaknesses of the technologies can be compensated while exploiting the strengths of both sensors. A system combining accelerometers and video tracking demonstrates accurate registration even during rapid head motion.[11]

\subsubsection{Passive technologies}

Passive technology does not require transmitters, but uses existing environmental signals, e.g. the magnetic field of the Earth. Artificial passive signals can be added to the environment, too. The advantage is the simplicity of the system and the implicit support of multiple devices. The disadvantage is poor accuracy and, in the case of optical localization, the dependence on the quality of the lighting.[12]

\section{$3 \quad$ Field of application}

As mentioned before, AR can be used in many fields, such as medicine, military, marketing, navigation, aviation, maintenance, assembly, repair and others.

In medical sector AR has considerably contributed to risk reduction. For instance, scanning of the patient in real-time and sharing this information with specialists not present during the surgery can cause significant efficiency improvement.

Combination of AR principle and GPS in the smartphones greatly raises the comfort of the user experience in navigation.

Relatively well-known military application of AR is so called Tactical Augmented Reality (TAR). TAR is supposedly going to radically transform military operations and information access from military training and information sharing among the squads to segmented vision in operation. [14]

Marketing is a very important field of use. As it appeals to different senses of the customer and creates emotional attachment it is a very important marketing tool with big potential. That is why currently clothing, cosmetics and furniture companies make use of AR opportunities. Example of marketing application is shown in the Figure 3. [15] 


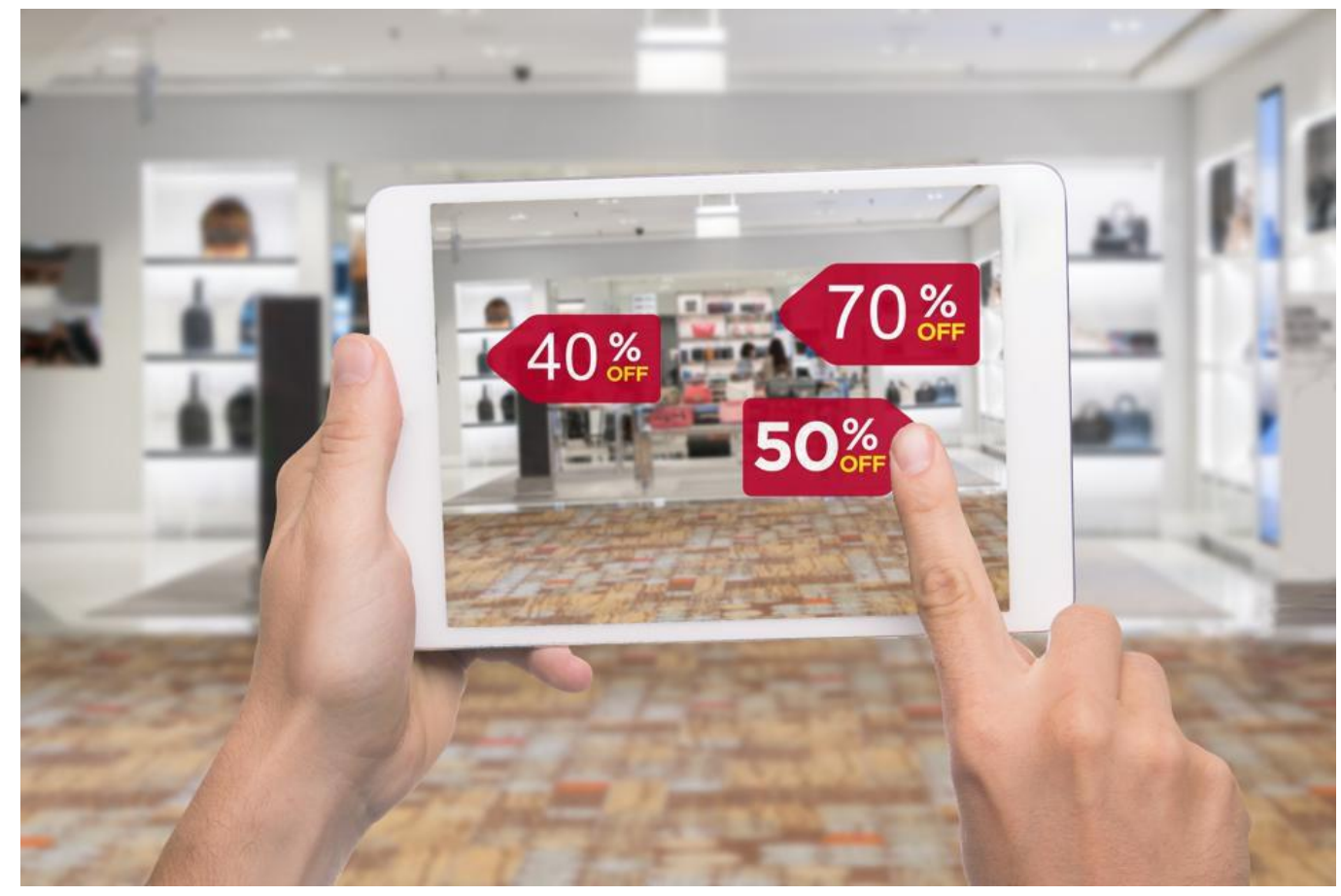

Figure 3 - Example of AR Marketing Applications

In the following section industrial $A R$ and its application in manufacturing will be defined more deeply.

\subsection{Manufacturing}

New product development and implementation is an extremely complex process greatly dependent on proper exploitation of Computer-aided systems (CAD). In addition, companies in manufacturing industry also use Computeraided manufacturing systems (CAM). It is necessary for companies aiming to achieve the maximal profit to utilize modern technologies. The pressure on manufacturing plants and their production processes increases to produce new innovative products with great productivity and efficiency, with excellent quality and at the same time at the lowest costs and lead time as possible. Moreover, environmental regulation and corporate social responsibility are becoming more limiting. In order to maintain competitiveness, it is needed to constantly innovate processes to minimize costs, maximize profits and satisfy customers' needs. AR presents a tool which can be used by manufacturing companies to keep up with the demanding trend.

Main fields of application of AR in manufacturing are Assembly, Quality Control, Automation or Repair and Automation.

\subsection{Assembly}

Complex assembly is an essential process in modern manufacturing. The number of components which need to be assembled together in often very complicated and precise sequence of operations within a very short time can be very challenging. Implementation of AR system in this area can reduce the 
need to study pdf or video manual and can replace it by interactive instructions, example shown in Figure 4. [16]

Three main features used in assembly process support can be described: audio support, enhanced text and interactivity. Since the quality of the assembly operations strongly depends on the quality of the information in the AR system it is necessary to correctly select and set the AR system.

Text and its integration are very often an essential part of the AR supporting system. It contains important additional information needed to correctly perform the task.

Audio support eliminates mistakes caused by poor vision. Audio signals are very helpful especially during training of new operators.

Interactive AR support when performing assembly tasks is very comfortable for the users as they can interact with the 3D features placed over real environment in real time. [17]
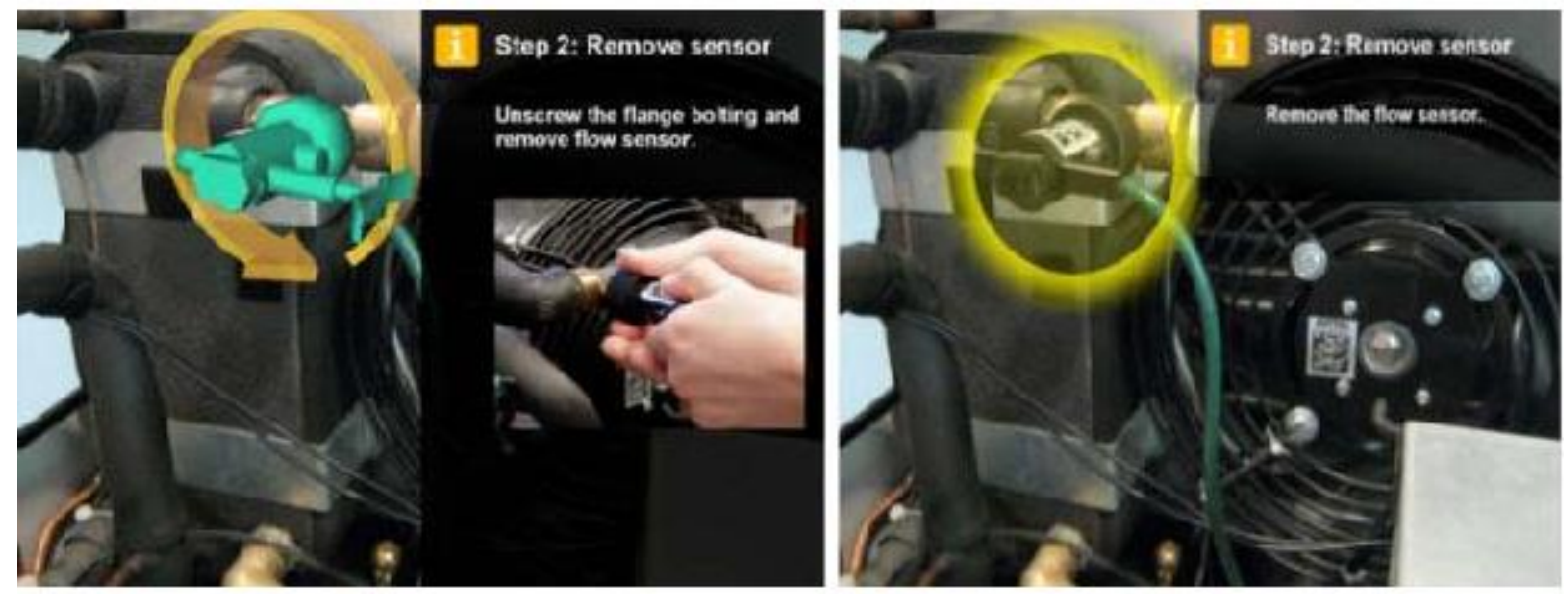

Figure 4 - Assembly and Maintenance Workflow with AR

\subsection{Maintenance}

Maintenance support through AR system in manufacturing is relatively well developed. First reference to first AR maintenance operation was described by Feiner [18]. Because of the AR maintenance support, it is often no more needed to call a service technician when a machine fails. Through AR technology the machine can be scanned and the defect detected. Moreover, the repair instructions can be projected in real- time into the real-surroundings without the need to study long and detailed documents. [16]

In case of complicated machine failure, the needed external expert does not have to travel to the plant to examine the machine. The expert can assist the worker through AR system to perform the maintenance tasks. This fact should presumably increase the efficiency of the experts as they can support more issues at the same time without the need to travel to the site. The costs and the time consumption connected with the travelling of the experts are therefore eliminated. [19] 


\subsection{Automation}

Automation is an AR technology of great importance. With the recent progress in smart manufacturing more jobs are being automated. A big influence has AR systems mainly in robot programming (see Figure 5). In order to correctly programme industrial robot, it is needed to respect faultlessly the working space both in real and virtual environment. AR technology contributes to increase safety of the operators. Also, it helps to improve the skills of the workers. Correctly set AR system in robot collaboration can significantly enhance productivity in manufacturing industry. [5]

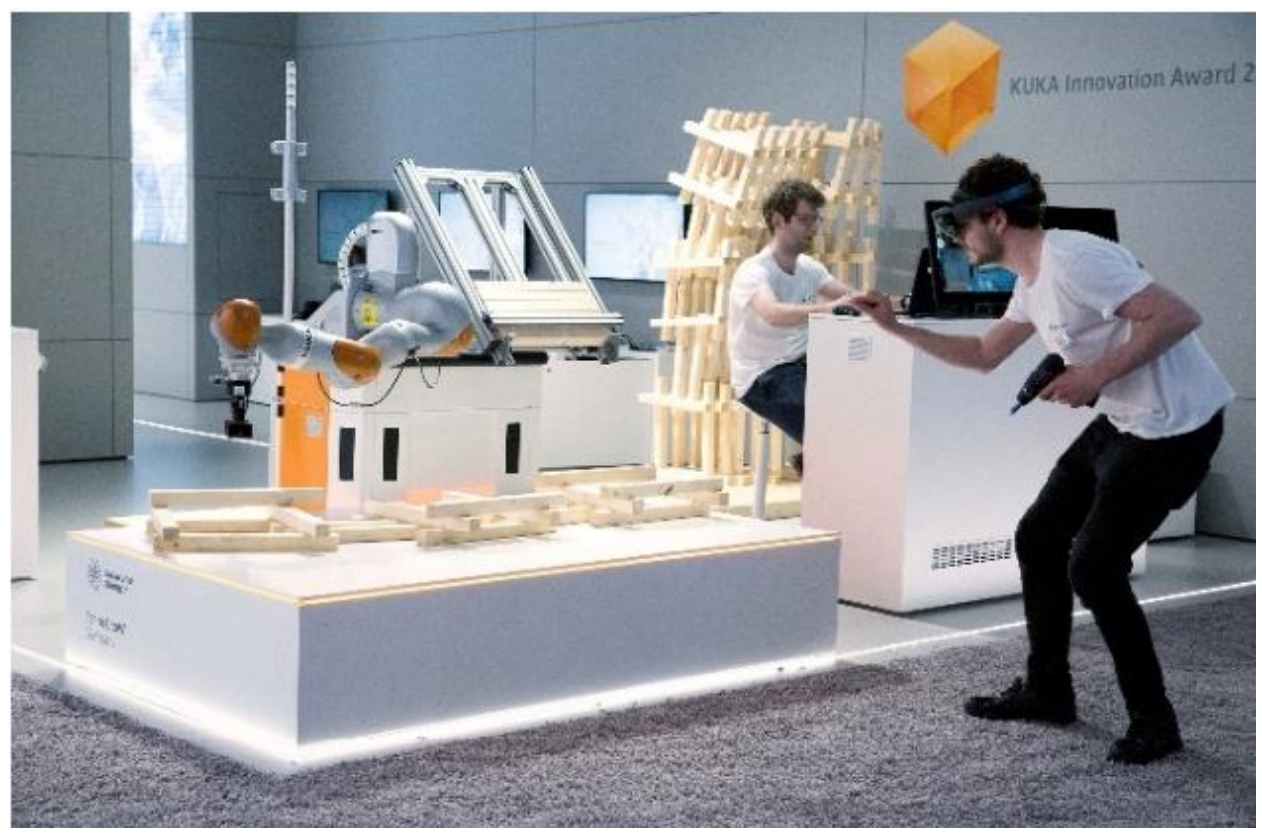

Figure 5 - Automation with AR

\subsection{Quality control}

Development and production of the product is a very complex process from conception and designing to realisation. Although improvement in productivity or efficiency is a big topic in manufacturing industry, quality of the final product is a must which cannot be jeopardized. Any correction of defect at any stage of the production is very uneconomical. When a defect occurs, it must be detected as soon as possible. Any lag between the creation and detection of the defect raises extremely the costs concerned. In the worst scenario when the defect gets through to the customer, not only are the costs extremely high, but also the customers' confidence in the company and its products is threatened. Quality control procedures are therefore a huge priority in manufacturing industry. AR presents an effective solution to manage quality at various levels of production process.

As the variety and complexity of the products increases, the quality control is much more demanding and concerning limitations of human inspectors it can become less effective. AR technology provides an interesting solution as the inspectors are enabled to directly compare real product with its ideal visual 
model. AR systems in quality inspection are used for instance in companies Bosch or Porsche. [21]

\subsubsection{Training}

One of the most expanded areas of implementation of IAR is Training. Augmented and virtual reality technologies increase the level of training programmes in plants and supplement the missing qualifications through more effective training of the new workforce. Training of new employees is 30 to $40 \%$ more efficient and contributes to shortening the assembly time.[27]

Companies that were the first to use augmented and virtual reality in manufacturing are proving the usefulness of these technologies in supplementing skills and in changing the way management technicians are trained and evaluated as older workers retire in order to retain and share professional knowledge and intellectual property.[26] Augmented and virtual reality also prove their usefulness in increasing employee productivity and safety (see Figure 6).[28]

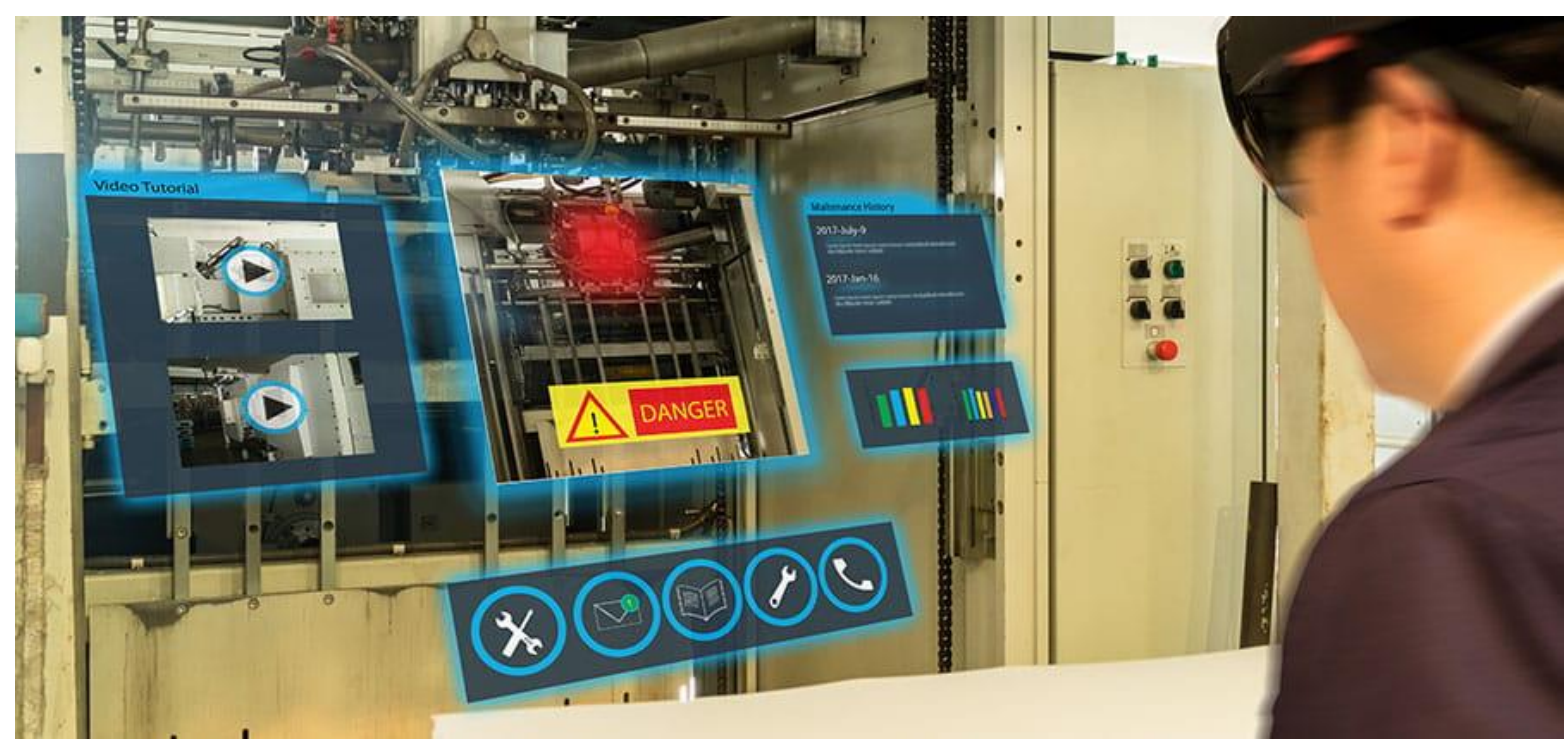

Figure 6 - Safety Improvement with AR

Manufacturers have been facing a shortage of skilled workers for years, even before a period of record low unemployment. The reasons are workers' retirement, business expansion and deepening skills shortages.

The most difficult positions to fill are usually those that have the greatest impact on the operation of the company. Technical positions such as management technicians, skilled operators, mechanics and engineers are critical to expanding operations, implementing digital transformation initiatives and increasing productivity. These are also the positions that require the most training and investment.

Internal training programs are the key to attracting and developing the workers that manufacturers need. However, traditional methods, such as training manuals, imitation learning, or assessment and certification 
processes, are often considered to be obsolete, inefficient, and time consuming. These methods also address the need to take into account different learning styles - visual, listening, verbal, etc.[7]

\section{$4 \quad$ Augmented Reality in Industry $\mathbf{4 . 0}$}

Industrial $A R$ is considered a central part of the fourth industrial revolution initiatives. Generally, its main contribution is the fact, that the operators can relatively easily access the relevant digital information and compare this information with the real product in real environment and in real time. Therefore, AR allow the workers to eliminate the difference between the real and virtual world.

\subsection{Augmented Reality Trends in Industry $\mathbf{4 . 0}$}

At the moment, the estimated annual growth rate of IAR market is projected of around $74 \%$ in the period 2018-2025. [23] The aggregated market of industrial AR is projected to reach 76 billion USD in 2025 [23]. The precise development is dependent on the speed of growth and progress of AR systems.

In general, it is agreed that importance and potential of AR are very high. However, the authors agree that the implementation in practical applications in manufacturing is relatively very challenging. Most of the research confirm the improvement of features connected with the application of AR in industrial task (example of application is shown in Figure 7) [24]. That means that when an industrial operation is supported with AR technology, the task is most likely completed in shorter time and with lower error risk. Studies show the importance of the correct task and worker selection. Generally, experts show that the positive impact of AR systems are lower by specialists, on the other hand it is relatively higher with untrained operators. 


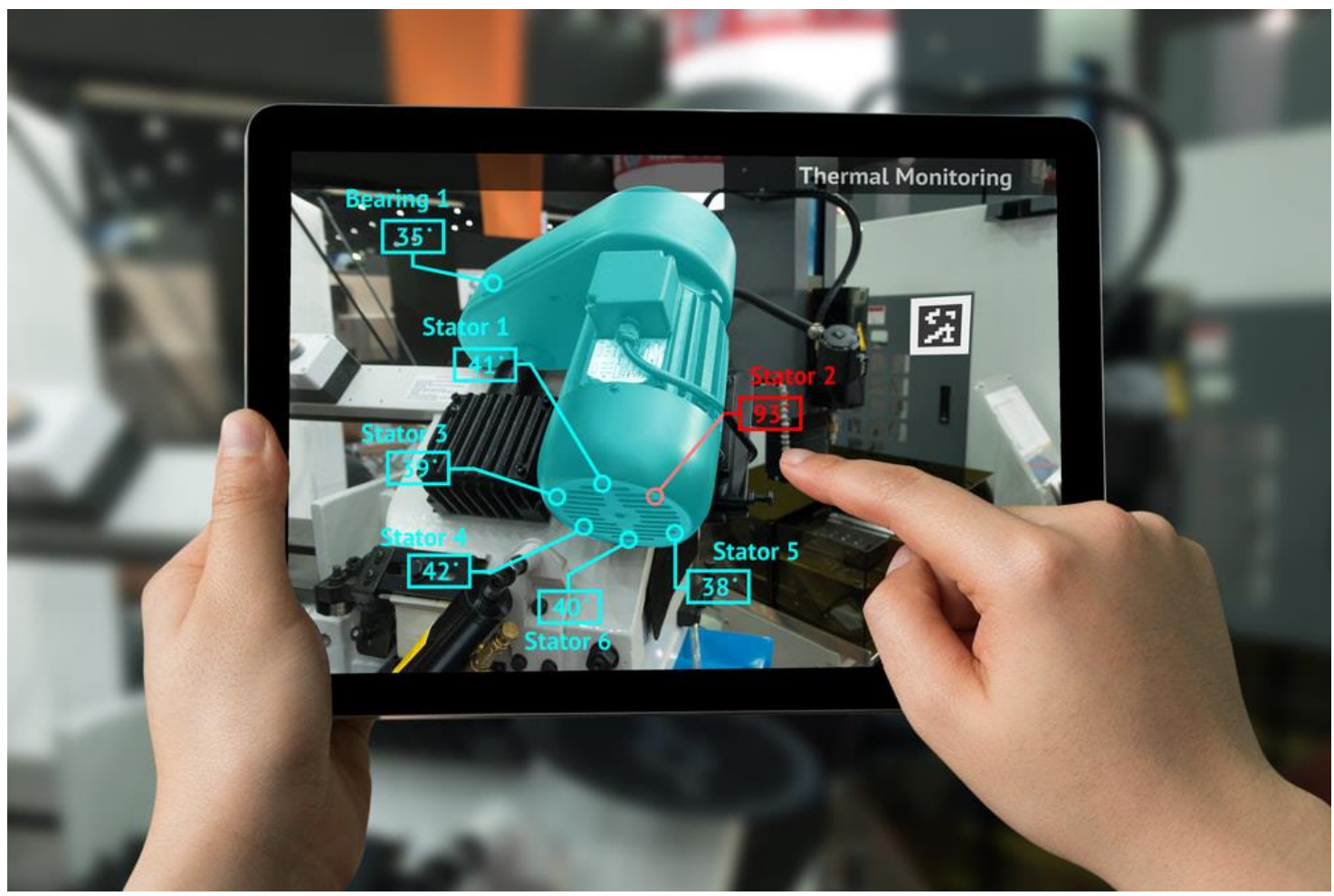

Figure 7 - Example of smart factory

However, there are still aspects preventing the widespread adoption of AR, mostly concerning acceptance tasks and usability. Even though the operation supported by AR technology have supposedly higher rate of efficiency both regarding time and quality the influence of $A R$ on performance is strongly connected with the complexity and nature of the operation performed. Moreover, the studies confirm that the level of expertise and experience of the workers have also a significant impact. Generally, the lack of methodology to measure impact of AR on workers' performance in manufacturing industry is considered one of the biggest limitations of widespread AR application.

Industrial AR belongs to key pillars of the Industry 4.0. It enables the connection of workers with the physical world while overlaying the real-world scene with the digital information.

Even though the AR market is quickly rising, the wide adoption in industry is still relatively low. The industrial digitalisation and Industry 4.0 in general exploit the opportunities of new emerging technologies. In spite of increasing importance of intelligent automation, the workers are still the crucial part of the manufacturing operations.

Even though, one of the key principles of the Industry 4.0 is to enable the automation and digitalisation of the manufacturing processes, the importance of the workers, their knowledge and the possibility of working in smart factories with intelligent manufacturing environments is strongly emphasised.[25]

The EU classified already in 2015 Industrial Augmented Reality as one of the main technologies which will drive the smart factories development. 
Longo [26] sees the main opportunity of IAR in the human-machine interactions enabled through visualising interactive and contextual information.

Many companies nowadays consider AR to be important opportunity to provide new services to their customers related to their products.

According to Wang IAR enables a substantial efficiency benefit by providing flexible real-time information and the possibility of obtaining information hands-free. IAR at the same time contributes to error rate decrease. Moreover, it offers an easy way to communicate with experts regarding technical support. [27]

\subsection{Benefits}

Augmented reality addresses the needs of diverse learning styles and has many benefits. Augmented reality:[25]

- $\quad$ helps workers to orient themselves more effectively when navigating the plant and warehouse;

- $\quad$ provides step-by-step instructions;

- $\quad$ identifies the appropriate tools and parts needed for the task;

- $\quad$ projects an overlay of key performance indicators and operational data directly onto the device to show how the plant is responding to change.

- $\quad$ ensures the visual, listening and kinaesthetic nature of teaching;

- provides real-time visual and oral instructions;

- during work, warns of corrective actions and corrects them, provides real-time feedback;

Augmented reality provides the means to combine the best of both assessment methods. Students are subjected to practical tests and at the same time valuable data necessary for improving training are captured. Augmented reality can detect if the wrong part was used, if the assembly steps were performed in the wrong order, if the operation takes too long, and even if the incorrect step caused a safety risk.[10]

With the use of augmented reality, the effectivity of the transfer of expertise can be increased. Instead of performing the process and devoting hours of work to documenting it, skilled technicians can create an augmented reality experience in a passive way. Augmented reality uses advanced sensors and computer vision technology to capture image and sound, while allowing to document the plant's place and work processes. Management technicians can perform the action with the headset on and comment on their actions as if they were training someone else. At the same time, augmented reality documents and transmits information into training materials for future use, 
which can be published either as an augmented reality experience or in more traditional formats such as video, photographs and text documents.

In addition to an effective departure process, augmented reality can address skills shortages by creating connections between remote professionals and manufacturing plants. It also provides more flexibility for workers who are entitled to retire but may wish to continue working part-time or remotely.[10]

\subsection{Challenges and limitations of AR}

While the potential of the IAR is great and eventually very beneficial for manufacturing companies, there are many limiting factors that cause still a relatively low portion of projects and prototype which successfully work in the industry processes.

The main challenge of the AR application is to increase the portion of the prototypes matured successfully into the practical world.

Azuma divides the limitations into three following groups:[7]

- Technological

- User interface

- Social acceptance

As the biggest limit to wider expansion of the AR the technological limitations are seen. In order to enable the wide deployment of AR, the systems must be as light, cheap, accurate and little power consuming as possible.

One of these limits is also processing speed. In order to support the complex tracking solutions, the processing power must be increased.

The user interface is also being stressed out since the representation of the data and optimal interaction of the user with the data acquired by AR systems is essential.

Another crucial challenge of the tracking is the low latency. The system delay is the root cause of the most registration errors.

Another big issue is ergonomics. Especially hands-free systems, typically head-mounted displays need their ergonomics to be improved. Despite the effort to optimise these devices, the weight is still a limiting factor which must be resolved. Moreover, the visibility of the content also needs improvements as well as the very high-power consumption, insufficient field of view or options of working outside of the lab conditions.

For widespread adoption, AR systems should be integrated into the existing IT infrastructure seamlessly.

In connection with aspirations of wide acceptance of AR applications there are social issues to be solved. A very sensitive and crucial issue are the privacy concerns. However, some authors also point out for instance concerns connected with fashion aspects and willingness of the users to wear the device. 
One of the most crucial questions is the user acceptance when implementing the new technology. The privacy concern when using AR is of great importance. It is still relatively unclear which measures should be taken to counteract the privacy concerns from the user perspective. [25]

\section{Summary}

The Industry 4.0 is most certainly lead to relatively major changes in society, trade, economy, education as well as in manufacturing. While industry keeps moving and changing towards increased digitalisation and development of smart factories, the intelligent manufacturing tools, concepts and technologies must support this progress. A very promising technology which could in the future help with interaction of workers with the digital world of the smart factories is Augmented Reality. However, there are still some limits and obstacles in wide use of AR in manufacturing processes and it has not yet been prepared for deployment in some industrial areas, it is already used in other areas with good success. Nevertheless, the research context regarding AR concepts is increasing and the current obstacles and limits might be in the upcoming years overcome.

\section{Acknowledgment}

This paper was created with the support of an internal grant from the University of West Bohemia project number SGS-2018-031 entitled Optimization of the sustainable production system parameters.

\section{References}

[1] MILGRAM, P., COLQUHOUN, H. A Taxonomy of Real and Virtual World Display Integration. University of Toronto, Canada, 2001.

[2] MILGRAMT, P., KISHINOTT, F. Special issue on networked reality. IEICE Trans. Inf. Syst. 1994, 77(12), 1321-1329.

[3] HOOVER, M. An evaluation of the Microsoft HoloLens for a manufacturingguided assembly task. lowa, 2018. Graduate Theses and Dissertations. lowa State University.

[4] CARMIGNIANI, J., FURHT, B., ANISETTI, M., CERAVOLO, P., DAMIANI, E., IVKOVIC, M. Augmented reality technologies, systems, and applications. Multimedia tools and applications, 2011, 51(1), 341-377.

[5] RAUSCHNABEL, P. A., He, J., Ro, Y. K. Antecedents to the adoption of augmented reality smart glasses: a closer look at privacy risks. J. Bus. Res., 2018, 92, 374-384.

[6] CRAIG, A. B. Understanding Augmented Reality: concepts and applications. Amsterdam: Elsevier, 2013.

[7] AZUMA, R., BEHRINGER, R., FEINER, S., JULIER, S., MACINTYRE, B. Recent advances in augmented reality. IEEE Comput. Graph. Appl., 2001, December, 34-47 . 
[8] ROLLAND, J. P., FUCHS, H. Optical versus video see-through headmounted displays in medical visualization. Presence: Teleoperators \& Virtual Environments, 2000, 9(3), 287-309.

[9] PALMARINI, R., ERKOYUNCU, J.A., ROY, R., TORABMOSTAEDI, H. A systematic review of augmented reality applications in maintenance. Robot. Comput. Integr. Manuf., 2018, 49, 215-228. https://doi.org/10.1016/j.rcim.2017.06.002.

[10] BHATTACHARYA, B., WINER, E. A method for real-time generation of augmented reality work instructions via expert movements. In: M. Dolinsky, I.E. McDowall (Eds.), The Engineering Reality of Virtual Reality, 2015. doi: http://dx.doi.org/10.1117/12.2081214.

[11] YOKOKOHJI, Y., SUGAWARA, Y., YOSHIKAWA, T. Accurate Image Overlay on Video See-through HMDs Using Vision and Accelerometers. Proc. IEEE Virtual Reality, 2000, 247-254.

[12] KIYOKAWA, K., KURATA, Y., OHNO, H. An Optical Seethrough Display for Mutual Occlusion of Real and Virtual Environments. Proc. Int'l Symp. Augmented Reality 2000 (ISAR 00), 2000, 60-67.

[13] Spatial Mapping. Unity [online]. 2020 [cit. 2020-09-07]. Available: https://docs.unity3d.com/2018.3/Documentation/Manual/SpatialMappingCo mponents.html

[14] RUBLOWSKY, S. J., CRYE, C. C. U.S. Patent No. 9,677,840. Washington, DC: U.S. Patent and Trademark Office, 2017.

[15] Augmented Reality: Eight AR Marketing Applications For Brands In 2019. Forbes [online]. 2019 [cit. 2020-09-07]. Available: https://www.forbes.com/sites/theyec/2019/09/17/augmented-reality-eight-armarketing-applications-for-brands-in-2019/\#1a8ff66e1b3b

[16] WEBEL, S. et al. Augmented Reality Training for Assembly and Maintenance Skills. BIO Web of Conferences, 2011. doi: 10.1051/bioconf/20110100097

[17] WANG, Y., ZHANG, S., YANG, S. et al. Mechanical assembly assistance using marker-less augmented reality system. Assembly Automation, 2018, 38, 77-87.

[18] FEINER, S., MACINTYRE, B., SELIGMANN, D. Knowledge-based augmented reality. Communications of the ACM, 1993, 36(7), 53-62.

[19] MOURTZIS, D., ZOGOPOULOS, V., VLACHOU, E. Augmented Reality Application to Support Remote Maintenance as a Service in the Robotics Industry. Procedia CIRP, 2017, 63, 46-51.

[20] KYJÁNEK, O. et al. Implementation of an Augmented Reality AR Workflow for Human Robot Collaboration in Timber Prefabrication. Proceedings of the 36th ISARC, 2019, 1223-1230. doi:

https://doi.org/10.22260/ISARC2019/0164

[21] BOSCH, T., KÖNEMANN, R., de COCK, H., van RHIJN, G. The effects of projected versus display instructions on productivity, quality and workload in a simulated assembly task. Proceedings of the 10th International 
Conference on Pervasive Technologies Related to Assistive Environments, 2017, 412-415.

[22] YOU, S., NEUMANN, U., AZUMA, R. Hybrid Inertial and Vision Tracking for Augmented Reality Registration. Proc. IEEE Virtual Reality, 1999, 260-267.

[23] BIS Research. Global Augmented Reality and Mixed Reality Market: Analysis Forecast 2018-2025, 2018.

[24] Augmented Reality: Exponential Technologies in the Smart Factory [online]. [cit. 2020-09-07]. Available: http://strategy4.org/my-blog/augmented-realityexponential-technologies-in-the-smart-factory

[25] MASOOD, T., EGGER, J. Augmented reality in support of Industry 4.0: Implementation challenges and success factors. Robotics and Computer Integrated Manufacturing, 2019, 58, 181-195. doi: https://doi.org/10.1016/j.rcim.2019.02.003.

[26] LONGO, F., NICOLETTI, L., PADOVANO, A. Smart operators in Industry 4.0: A human centred approach to enhance operators' capabilities and competencies within the new smart factory context. Computers \& Industrial Engineering, 2017, 113, 144-159.

[27] WANG, X., ONG, S. K., NEE, A. Y. C. A comprehensive survey of augmented reality assembly research. Advances in Manufacturing, 2016, 4(1), 1-22.

[28] Four ways Industry 4.0 technology can improve Safety. PTC [online]. [cit. 2020-09-07]. Available: https://www.ptc.com/en/thingworx-blog/4-waystechnology-can-improve-worker-safety 